\title{
Utilização de leveduras vivas (Saccharomyces cerevisiae) visando à produção de cordeiros Ile de France superprecoces em sistema de creep-feeding
}

\author{
Effect of utilization of yeast (Saccharomyces cerevisiae) for feeding Ile de France lambs \\ in creep-feeding system
}

\author{
Mikael Neumann ${ }^{\mathrm{I}}$ Paulo Roberto Ost ${ }^{\mathrm{II}}$ Luiz Giovani de PellegriniI ${ }^{\mathrm{II}}$ Sávio Etiene Grassi de Mello ${ }^{\mathrm{II}}$ \\ Marco Antônio Almeida da Silva ${ }^{\text {II }}$ José Laerte NörnbergII
}

\section{RESUMO}

O experimento foi conduzido no Núcleo de Produção Animal da Universidade Estadual do Centro Oeste do Paraná (UNICENTRO) com o objetivo de avaliar o efeito do nível de suplementação de leveduras vivas secas (Saccharomyces cerevisiae) sobre o consumo médio diário de concentrado e o ganho de peso médio diário de cordeiros, em sistema de creep-feeding. Foram testados os seguintes tratamentos: $T_{1}-0 \mathrm{~g}$ animal ${ }^{-1}$ dia $^{-1} ; T_{2}-0,4 \mathrm{~g}_{\text {animal }^{-1}}$ dia $^{-1} ; e T_{3}$ - 0,8 animal $^{-1}$ dia $^{-1}$. Foram utilizados 27 cordeiros Ile de France de partos simples (18 machos e nove fêmeas) com peso vivo médio inicial de $19,5 \mathrm{~kg}$ e idade média de 40 dias. O creep-feeding compreendeu três períodos de 21 dias, totalizando 63 dias de suplementação. Não houve interação significativa $(P<0,05)$ entre nível de suplementação e período de avaliação quanto ao consumo de concentrado, ganho de peso médio diário e eficiência de transformação de $g$ de concentrado por $100 \mathrm{~g}$ de ganho de peso. Não houve diferenças quanto à suplementação de leveduras vivas variando o nível de 0 a $0,8 \mathrm{~g}$ animal $^{-1}$ dia $^{-1}$ sobre o consumo de concentrado $\left(635,7 \mathrm{~g} \mathrm{dia}^{-1}\right)$ e ganho de peso (418g dia $^{-1}$ ) de cordeiros Ile de France nascidos de parto simples em sistema de creep-feeding, em função do nível de suplementação de leveduras vivas secas.

Palavras-chave: consumo de concentrado, ganho de peso, produção de leite.

\section{ABSTRACT}

The experiment was conducted at the Núcleo de Produção Animal of the Universidade Estadual do Centro Oeste do Parana (UNICENTRO). The trial aimed to evaluate the effect of living yeast (Saccharomyces cerevisiae) on dry matter intake of concentrate and performance of lambs kept in the creep-feeding system, submitted to the following treatments:
$T_{1}$ - Og animal ${ }^{-1}$ day $^{-1} ; T_{2}-0.4$ g animal $^{-1}$ day $^{-1} ; e T_{3}-0.8 g$ animal ${ }^{-1}$ day $^{-1}$. Twenty-seven lambs Ile de France of simple birth with an average age of 40 days and average live weight of $19.5 \mathrm{~kg}$ were used. The whole supplementation period in creepfeeding was 63 days, divided in three periods of 21 days. No significative interaction was observed between supplementation of level of the yeast and evaluation period for average daily dry matter intake of concentrate, for average daily weight gain and feed conversion of the $\mathrm{g}$ of concentrate by $100 \mathrm{~g}$ weight gain. No difference of supplementation of level of the yeast for average daily dry matter intake of concentrate $\left(635.7 \mathrm{~g} \mathrm{day}^{-1}\right)$ and average daily weight gain (418g day ${ }^{-1}$ ) for Ile de France lambs simple birth on creep-feeding system, according to supplementation of living yeast.

Key words: intake of concentrate, milk production, weight gain.

\section{INTRODUÇÃO}

A produção mundial de carne ovina de 2004 a 2006 cresceu 6,5\%, significando um bom avanço relativo entre demais tipos de carne, embora ainda represente apenas 5\% do volume total de carnes comercializadas (ANUALPEC, 2006). Tal constatação tem levado o produtor rural da região Sul do Brasil, que atualmente trabalha com um rebanho de 5,1 milhões de cabeças (ANUALPEC, 2006), a direcionar maiores investimentos na criação ovina, principalmente na produção de cordeiros precoces com adição de concentrados às dietas alimentares.

IPrograma de Pós-graduação em Produção Vegetal, Setor de Ciências Agrárias e Ambientais, Universidade Estadual do Centro-Oeste do Paraná (UNICENTRO). Rua Simeão Camargo Varela de Sá, 03, 85040-080, Guarapuava, PR, Brasil. E mail: mikaelneumann@hotmail.com. Autor para correspondência.

IICurso de Medicina Veterinária, UNICENTRO, Guarapuava, PR, Brasil.

IIIPrograma de Pós-graduação em Zootecnia, Universidade Federal de Santa Maria (UFSM), Santa Maria, RS, Brasil. 
Os probióticos têm sido constantemente utilizados visando ação reguladora da flora intestinal e manutenção do equilíbrio entre flora benéfica e microorganismos patogênicos no intestino. As leveduras vivas (Saccharomyces cerevisiae) auxiliam na manutenção do pH no rúmen via estímulo de bactérias utilizadoras de lactato e contribuem com constante suprimento de nutrientes para a população bacteriana no intestino (ROSE, 1997). O pH para crescimento ótimo da Saccharomyces cerevisiae está com aproximadamente 4,5 (ROSE, 1997). No rúmen, em pH entre 6,0 e 6,5, a taxa de crescimento do fungo é reduzida, porém, capacita-o à secreção de compostos químicos como nucleotídeos, aminoácidos e enzimas, assim como de enzimas hidrolíticas, mais profusamente. Ressalta-se ainda que a atividade respiratória da Saccharomyces cerevisiae (200 a 300 $\mathrm{mmol} \mathrm{min}^{-1} \mathrm{~g}^{-1}$ ) é de ordem de magnitude maior que a concentração de oxigênio no fluído ruminal e, assim, pequenas quantidades de levedura $\left(1,33 \mathrm{~g} \mathrm{~L}^{-1}\right)$ incluídas às dietas de ruminantes poderiam ser benéficas (NEWBOLD et al., 1995).

Em revisão de literatura, TRICARICO (2005) constatou que diversos trabalhos de pesquisa mostraram aumento da produtividade animal, de carne ou de leite, por meio do uso da Saccharomyces cerevisiae, sendo, segundo DAWSON \& HOPKINS (1992) e NEWBOLD et al. (1996), resultado de sua capacidade de estimular a multiplicação de bactérias ruminais anaeróbicas totais, bactérias celulolíticas e bactérias utilizadoras de ácido láctico no rúmen, que conseqüentemente, altera o metabolismo e melhora os processos de digestão da porção fibrosa da dieta. DAWSON (2000) verificou que o aumento na digestibilidade das fibras resultou em maior volume total de fibras digeridas no rúmen, com maior ingestão de matéria seca e melhor desempenho produtivo.

Conforme CALLAWAY \& MARTIN (1997) isso ocorre devido aos fatores relacionados ao fornecimento contínuo de vitaminas (complexo B e ácido para-amino benzóico), de ácidos dicarboxílicos (fumarato, malato etc.), remoção de $\mathrm{O}_{2}$, maior efeito tampão (bactérias celulolíticas preferem $\mathrm{pH}>6$ ) e redução no número de protozoários. Com esta resposta de otimização do meio ruminal, prevê-se aumento na ingestão de matéria seca, maior ganho de peso, melhor conversão alimentar e menores problemas metabólicos (DOREAU \& JOUANY, 1998).

O objetivo do experimento foi avaliar o efeito do nível de suplementação de leveduras vivas secas $\left(0,0,4\right.$ e $0,8 \mathrm{~g}$ animal $^{-1} \mathrm{dia}^{-1}$ de Saccharomyces cerevisiae) sobre o consumo médio diário de concentrado e ganho de peso médio de cordeiros Ile de France nascidos de parto simples, em sistema de creep-feeding.

\section{MATERIAL E MÉTODOS}

O experimento foi conduzido na Fazenda Capão Bonito, Distrito de Entre Rios, localizada no município de Guarapuava, Paraná (PR), no período de 03/08 a 01/11/2005. O clima da região de GuarapuavaPR é o Cfb (Subtropical mesotérmico úmido), sem estação seca, com verões frescos e inverno moderado, conforme a classificação de Köppen, em altitude de aproximadamente $1100 \mathrm{~m}$, precipitação média anual de $1944 \mathrm{~mm}$, temperatura média mínima anual de $12,7^{\circ} \mathrm{C}$, temperatura média máxima anual de $23,5^{\circ} \mathrm{C}$ e umidade relativa do ar de 77,9\%. Cartograficamente, localiza-se a $25^{\circ} 23^{\prime} 26^{\prime \prime}$ de latitude Sul e $51^{\circ} 27^{\prime} 15^{\prime \prime}$ de longitude Oriental.

Foram avaliados três níveis de suplementação $\left(0,0,4\right.$ e $\left.0,8 \mathrm{~g}_{\text {animal }}{ }^{-1} \mathrm{dia}^{-1}\right)$ de levedura viva seca (Saccharomyces cerevisiae, cepa L11) na concentração 1 x 1010UFC g-1 (produto comercial Procreatin 7), na dieta alimentar de cordeiros Ile de France, em sistema de creep-feeding, junto às mães mantidas em dois hectares, subdivididos em oito piquetes de pastagem de aveia preta (Avena strigosa) e azevém comum (Lolium multiforum), com teor médio de MS de 18,86\% e manejada para manter uma disponibilidade média de $2326 \mathrm{~kg} / \mathrm{ha}$ de MS e oferta de forragem de $12 \%$ do peso vivo. Os lotes de animais foram rotacionados entre os piquetes a cada cinco dias, visando anular o efeito de ambiente.

Foram utilizadas 27 ovelhas da raça Ile de France, com peso vivo médio inicial de $99,3 \mathrm{~kg} \pm 3,4 \mathrm{~kg}$ e idade de 43,5 meses \pm 4 meses e 27 cordeiros de partos simples (18 machos e nove fêmeas), com peso vivo médio inicial de $19,5 \mathrm{~kg} \pm 1$,2kg e idade média de 40 dias, sendo estes designados aleatoriamente em três grupos de nove animais cada, equilibrados por peso, sexo e idade para receberem os tratamentos. Os animais foram provenientes do mesmo rebanho, sendo que nasceram na mesma época de parição e foram manejados sempre da mesma forma.

A alimentação dos cordeiros compreendeu

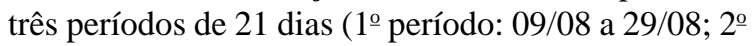
período: 30/08 a 19/09 e 3o período: 20/09 a 10/10), totalizando 63 dias de suplementação. Os animais (cordeiros e ovelhas) no início do experimento foram submetidos a um período de 15 dias de adaptação à pastagem de aveia preta mais azevém e ao sistema de manejo das dietas experimentais. Neste período, realizou-se a aplicação de um vermífugo de amplo espectro.

Os cordeiros foram separados duas vezes ao dia das ovelhas e direcionados ao creep-feeding 
para receberem as leveduras vivas secas misturadas ao concentrado fornecido na forma ad libitum, considerando uma sobra de $5 \%$ da matéria seca oferecida em relação à consumida, nos horários das $8 \mathrm{~h}$ às $10 \mathrm{~h}$ e das $17 \mathrm{~h}$ às $19 \mathrm{~h}$. O consumo voluntário do concentrado foi registrado diariamente por meio da pesagem da quantidade oferecida e das sobras do dia anterior. O manejo alimentar utilizado para manter constante o nível de ingestão de leveduras vivas secas para cada tratamento avaliado constou do registro diário no fornecimento da quantidade dos concentrados associado com o ajuste semanal da concentração de leveduras vivas na composição do concentrado.

As instalações do creep feeding constaram de 27 baias, com uma área de $0,5 \mathrm{~m}^{2}$ cada baia $(0,5 \mathrm{x}$ $1,0 \mathrm{~m}$ ) para cada animal, onde cada baia representou uma unidade experimental, equipada com um comedouro de madeira para suplementação do cordeiro e um bebedouro metálico, regulado por bóia automática.

No momento da separação dos cordeiros para o creep-feeding, as ovelhas também receberam uma suplementação de concentrado na proporção de 0,7\% do peso vivo. Considerando as características bromatológicas da pastagem de aveia preta mais azevém, por simulação de pastejo, e dos alimentos contidos na fração concentrada, as dietas das ovelhas apresentaram média $14,5 \%$ de proteína bruta. $\mathrm{Na}$ tabela 1 são apresentadas a consituição percentual e a composição química dos concentrados utilizados na suplementação dos cordeiros em creep-feeding e das ovelhas lactantes. Os cordeiros foram pesados, após um jejum de sólidos de 6h, no início e no final do período experimental, com pesagens intermediárias correspondentes a cada período de avaliação.

No $45^{\circ}$ e $60^{\circ}$ dia pós-parto, foram verificadas as produções de leite das mães dos cordeiros submetidos ao sistema de creep-feeding pelo método indireto. Os cordeiros foram separados de suas mães por $12 \mathrm{~h}$, no período da tarde às $17 \mathrm{~h}$ no dia anterior à medição da produção de leite. Após jejum de sólidos de $12 \mathrm{~h}$, mediante acesso às suas mães, os cordeiros foram pesados individualmente antes e após o ato de mamarem, sendo obtida a produção de leite estimada pela diferença de peso dos cordeiros corrigida para $24 \mathrm{~h}$.

As variáveis avaliadas, nos três períodos de avaliação, foram: ganho de peso médio diário e o consumo médio diário de concentrado (g dia-1) dos cordeiros submetidos ao sistema de alimentação. Também foram avaliados os parâmetros: pesos iniciais e finais dos cordeiros e das ovelhas e produção média diária de leite das ovelhas.

Foram realizadas amostras dos concentrados de cada tratamento durante os períodos de suplementação dos cordeiros e das ovelhas (Tabela

Tabela 1 - Constituição percentual e composição química dos concentrados utilizados na alimentação dos cordeiros em creep-feeding e das ovelhas lactantes.

\begin{tabular}{|c|c|c|}
\hline \multirow{2}{*}{ Componentes } & \multicolumn{2}{|c|}{------------------'Categoria animal------------------ } \\
\hline & Cordeiros & Ovelhas \\
\hline Alimento: & \multicolumn{2}{|c|}{ Constituição do concentrado, \% } \\
\hline Milho grão moído grosso & 51,5 & 56,8 \\
\hline Aveia branca inteira machacada & 26,4 & 16,0 \\
\hline Farelo de soja & 17,1 & 23,8 \\
\hline Calcário calcítico & 3,0 & 0,9 \\
\hline Fosfato bicálcico & 0,0 & 0,6 \\
\hline Núcleo mineral comercial & 2,0 & 2,0 \\
\hline Total & 100,0 & 100,0 \\
\hline Parâmetro: & ---------C & --------- \\
\hline Proteína bruta & 14,12 & 14,65 \\
\hline Fibra em detergente neutro & 15,5 & 11,15 \\
\hline Extrato etéreo & 2,90 & 2,32 \\
\hline Matéria mineral & 5,47 & 5,73 \\
\hline $\mathrm{Ca}$ & 0,97 & 0,85 \\
\hline \multirow[t]{2}{*}{$\mathrm{P}$} & 0,52 & 0,47 \\
\hline & \multicolumn{2}{|c|}{ Mcal kg-1 de MS } \\
\hline Energia digestível & 3,155 & 3,319 \\
\hline
\end{tabular}

Fonte: Dados do experimento.

Ciência Rural, v.38, n.8, nov, 2008. 
1), para estimar os teores de matéria seca total (MS), de proteína bruta $(\mathrm{PB})$, de matéria mineral $(\mathrm{MM})$ e de matéria orgânica (MO), conforme AOAC (1995). Os teores de fibra em detergente neutro (FDN) foram determinados conforme método de VAN SOEST et al. (1991) com amilase termo-estável, enquanto que os teores de cálcio e fósforo foram determinados conforme TEDESCO et al. (1985). Para o cálculo de energia digestível (ED), foream utilizadas as equações descritas pelo ARC (1980), com base na DIVMO e matéria orgânica (MO).

O delineamento experimental foi 0 inteiramente casualizado, composto por três tratamentos $\left(0,0,4\right.$ e $0,8 \mathrm{~g}$ animal $^{-1} \mathrm{dia}^{-1}$ de Saccharomyces cerevisiae) e nove repetições, em que cada repetição foi composta por um animal. Os dados coletados para cada variável foram submetidos à análise de variância com comparação das médias, a 5\% de significância, por intermédio do programa estatístico SAS (1993). A análise de cada variável seguiu o modelo estatístico: $\mathrm{Y}_{\mathrm{ijk}}=\mu+\mathrm{NS}_{\mathrm{i}}+\mathrm{R}_{\mathrm{j}}\left(\mathrm{NS}_{\mathrm{i}}\right)+\mathrm{P}_{\mathrm{k}}+(\mathrm{NS} * \mathrm{P})_{\mathrm{ik}}+\mathrm{E}_{\mathrm{ijk}}$; em que $\mathrm{Y}_{\mathrm{ijk}}=$ variáveis dependentes; $\mu=$ média das observações; $\mathrm{NS}_{\mathrm{i}}=$ efeito do nível de suplementação de ordem "i", $\mathrm{R}_{\mathrm{j}}(\mathrm{NS})_{\mathrm{i}}=$ Efeito aleatório baseado na repetição dentro do nível de suplementação ( $\mathrm{NS}_{\mathrm{i}}$ ) (Erro a); $P_{k}=$ Efeito do período de avaliação de ordem "k", sendo 1 (primeiro período), 2 (segundo período) e 3 (terceiro período); (NS*P) $)_{i k}=$ Efeito da interação entre nível de suplementação de ordem "i" e período de avaliação de ordem "k"; e $E_{\mathrm{ijk}}=$ erro aleatório residual, assumindo distribuição normal média igual a zero e variância $\sigma^{2}$ (Erro b).

Os dados relativos ao desempenho animal também foram submetidos à análise de regressão polinomial, considerando as variáveis período de avaliação (variando de um a 63 dias) e nível de suplementação de levedura (variando de 0 a $0,8 \mathrm{~g}$ animal $^{-1}$ dia $^{-1}$ ), por intermédio do procedimento proc reg do programa SAS (1993).

\section{RESULTADOS E DISCUSSÃO}

Não houve interação significativa $(\mathrm{P}>0,05)$ entre nível de suplementação e período de avaliação para consumo diário de concentrado (CMDC), expresso em $g$ animal ${ }^{-1}$ dia $^{-1}$ e em porcentagem do peso vivo, ganho de peso médio diário e eficiência de transformação do concentrado consumido em ganho de peso (Tabela 2).

Não houve diferença $(\mathrm{P}>0,05)$ entre os níveis de suplementação de Saccharomyces cerevisiae para ganho de peso médio diário, mostrando valor médio geral de $418 \mathrm{~g}$ animal ${ }^{-1}$. Vários trabalhos de pesquisa
(PIRES et al., 1999; RIBEIRO et al., 2000; MONTENEGRO \& SIQUEIRA, 2002) reportam ganhos de peso variando de 50 a $250 \mathrm{~g}$ animal ${ }^{-1} \mathrm{dia}^{-1} \mathrm{com}$ outras raças ovinas, sendo inferiores ao presente estudo.

Para o consumo de concentrado (expresso em $g$ dia $^{-1}$ ) e conversão alimentar ( $g$ de concentrado $100 \mathrm{~g}$ de ganho de peso ${ }^{-1}$ ) dos cordeiros, em creepfeeding, houve diferença $(\mathrm{P}<0,05)$ entre os níveis de suplementação. Animais suplementados com $0,4 \mathrm{~g} \mathrm{dia}^{-1}$ de Saccharomyces cerevisiae tiveram menor consumo (598 contra $658 \mathrm{~g} \mathrm{dia}^{-1}$ ) e melhor conversão alimentar (148,9 contra 180,3g de concentrado $100 \mathrm{~g}$ de ganho de peso $^{-1}$ ) em relação aos animais suplementados com $0,8 \mathrm{~g}$ dia $^{-1}$ de Saccharomyces cerevisiae, não diferindo $(\mathrm{P}>0,05)$, no entanto, da dieta controle com consumo de concentrado de $651 \mathrm{~g} \mathrm{dia}{ }^{-1}$ e eficiência alimentar de 150,5 de concentrado $100 \mathrm{~g}$ de ganho de peso $^{-1}$. Esse fato pode estar parcialmente associado à maior produção de leite das ovelhas (Tabela 3). Pode-se inferir que houve efeito substitutivo ao concentrado, apesar de o consumo de concentrado, quando expresso em porcentagem do peso vivo, não mostrar diferença entre os níveis de suplementação com valor médio de 1,82\%. A análise dos dados médios por equações de regressão mostrou comportamento linear para CA, indicando redução de eficiência alimentar na ordem de $3,73 \mathrm{~g}$ de concentrado para cada $100 \mathrm{~g}$ de ganho de peso para cada $0,1 \mathrm{~g}$ de suplementação da levedura Saccharomyces cerevisiae; já para o CMDC $\left(\mathrm{g}_{\text {animal }}{ }^{-1}\right.$ dia $\left.^{-1}\right)$, o comportamento foi quadrático, observandose ponto de mínimo CMDC com a suplementação de 0,39g da levedura Saccharomyces cerevisiae.

Apesar do interesse crescente pelo uso de probióticos para ovinos, os resultados de pesquisa com levedura são variáveis (TRICARICO, 2005). Tal afirmação foi observada no presente estudo pela menor conversão alimentar, em condição de maior consumo diário de concentrado, dos cordeiros suplementados com 0,8g dia ${ }^{-1}$ de Saccharomyces cerevisiae, sendo que, nesse caso, os efeitos benéficos da inclusão de leveduras à dieta não terem sido suficientes para evitar a ocorrência de uma disfunções digestivas como a acidose ruminal subclínica. SANTOS et al. (2006) enfatizaram que o efeito benéfico da levedura ocorre apenas em dietas com alto teor de carboidratos solúveis e de parede celular altamente digestível, corroborando a hipótese de que o ambiente ruminal é melhorado com o uso deste aditivo. No entanto, vários fatores podem afetar o desempenho animal à suplementação com leveduras, destacando-se a presença de fatores causadores de estresse, nível de produção almejado, fase de desenvolvimento do animal, tipo de forragem disponível, estratégia de alimentação e proporção de 
Tabela 2 - Consumo médio diário de concentrado (CMDC), expresso em g animal ${ }^{-1}$ dia $^{-1}$ ou em porcentagem do peso vivo, ganho de peso médio diário (GPMD) e eficiência alimentar (CMDC/GPMD) dos cordeiros Ile de France, suplementados com diferentes níveis de Saccharomyces cerevisiae, a cada 21 dias de avaliação.

\begin{tabular}{|c|c|c|c|c|}
\hline \multirow{2}{*}{ Níveis de Suplementação } & & ave & \multirow[b]{2}{*}{$3^{0}$ Período } & \multirow{2}{*}{ Média } \\
\hline & $1^{\text {o }}$ Período & 2º Período & & \\
\hline & \multicolumn{4}{|c|}{-------------------------Consumo médio diário de concentrado (g animal'1 dia-1)----------------------- } \\
\hline $0 g$ dia $^{-1}$ & 218 & 567 & 1167 & $651 \mathrm{~B}$ \\
\hline $0,4 g$ dia $^{-1}$ & 211 & 537 & 1045 & $598 \mathrm{C}$ \\
\hline $0,8 \mathrm{~g} \operatorname{dia}^{-1}$ & 238 & 574 & 1161 & $658 \mathrm{~A}$ \\
\hline Média & 222 c & $559 \mathrm{~b}$ & 1124 a & \\
\hline \multirow[t]{2}{*}{ Equação de regressão } & \multicolumn{4}{|c|}{$\begin{array}{c}\mathrm{CMDC}=-60,2778+14,1949 \mathrm{D}\left(\mathrm{R}^{2}: 0,9893 ; \mathrm{CV}: 6,17 \% ; \mathrm{P}=0,0001\right)^{*} \\
\mathrm{CMDC}=650,7444-274,4444 \mathrm{~N}+353,6111 \mathrm{~N}^{2}\left(\mathrm{R}^{2}: 0,9913 ; \mathrm{CV}: 5,60 \% ; \mathrm{P}=0,0001\right)^{* *}\end{array}$} \\
\hline & & édio diário & $\%$ de peso vi & 180 \\
\hline $0 \mathrm{~g} \operatorname{dia}^{-1}$ & 0,93 & 1,72 & 2,72 & 1,79 A \\
\hline $0,4 \mathrm{~g} \operatorname{dia}^{-1}$ & 1,01 & 1,84 & 2,73 & $1,86 \mathrm{~A}$ \\
\hline $0,8 \mathrm{~g} \mathrm{dia}^{-1}$ & 0,98 & 1,72 & 2,75 & $1,82 \mathrm{~A}$ \\
\hline Média & $0,97 \mathrm{c}$ & $1,76 \mathrm{~b}$ & 2,73 a & \\
\hline \multirow[t]{2}{*}{ Equação de regressão } & \multicolumn{4}{|c|}{$\mathrm{CMDC}=0,4848+0,0273 \mathrm{D}\left(\mathrm{R}^{2}: 0,8338 ; \mathrm{CV}: 17,73 \% ; \mathrm{P}=0,0001\right)$} \\
\hline & ----- & de peso mé & $\left.\mathrm{mal}^{-1} \mathrm{dia}^{-1}\right)-$ & - \\
\hline $0 \mathrm{~g} \operatorname{dia}^{-1}$ & 387 & 523 & 423 & 444 A \\
\hline $0,4 \mathrm{~g} \operatorname{dia}^{-1}$ & 335 & 452 & 419 & $402 \mathrm{~A}$ \\
\hline $0,8 \mathrm{~g} \operatorname{dia}^{-1}$ & 381 & 497 & 347 & $408 \mathrm{~A}$ \\
\hline Média & $368 \mathrm{~b}$ & $491 \mathrm{a}$ & $396 \mathrm{~b}$ & \\
\hline \multirow[t]{2}{*}{ Equação de regressão } & \multicolumn{4}{|c|}{$\mathrm{GPMD}=131,6049+13,9374 \mathrm{D}-0,1284 \mathrm{D}^{2}\left(\mathrm{R}^{2}: 0,3179 ; \mathrm{CV}: 18,72 \% ; \mathrm{P}=0,0001\right)$} \\
\hline & --------- & nentar ( $\mathrm{g}$ de c & de ganho de & ---------- \\
\hline Og dia ${ }^{-1}$ & 57,0 & 110,7 & 283,7 & 150,5 B \\
\hline $0,4 \mathrm{~g} \operatorname{dia}^{-1}$ & 66,0 & 121,2 & 259,6 & $148,9 \mathrm{~B}$ \\
\hline $0,8 \mathrm{~g} \operatorname{dia}^{-1}$ & 63,1 & 124,8 & 352,9 & $180,3 \mathrm{~A}$ \\
\hline Média & $62,0 \mathrm{c}$ & $118,9 \mathrm{~b}$ & 298,7 a & \\
\hline \multirow{2}{*}{ Equação de regressão } & \multicolumn{4}{|c|}{$\mathrm{CA}=-27,9352+3,8335 \mathrm{D}\left(\mathrm{R}^{2}: 0,8017 ; \mathrm{CV}: 31,62 \% ; \mathrm{P}=0,0001\right)$} \\
\hline & \multicolumn{4}{|c|}{$\mathrm{CA}=144,9781+37,3167 \mathrm{~N}\left(\mathrm{R}^{2}: 0,2448 ; \mathrm{CV}: 16,83 \% ; \mathrm{P}=0,0303\right)$} \\
\hline
\end{tabular}

Médias seguidas de letras minúsculas diferentes na linha ou seguidas de letras maiúsculas na coluna diferem pelo teste Tukey (P<0,05).

* - D = dias de suplementação de leveduras vivas secas, variando de 1 a 63 dias.

** - $\mathrm{N}$ = nível de suplementação de leveduras vivas secas, variando de 0 a $0,8 \mathrm{~g}$ animal $^{-1}$ dia $^{-1}$.

volumoso:concentrado na dieta (VAN SOEST, 1984; EZEQUIEL et al., 2000), fatores estes controlados no presente trabalho de pesquisa.

Na análise do período de avaliação dos cordeiros (63 dias), independente do nível de suplementação de leveduras vivas, observou-se um comportamento linear crescente, para o CMDC, em g animal $^{-1} \mathrm{dia}^{-1}$ de $14,19 \mathrm{~g}$ ou em porcentagem do peso vivo de $0,03 \%$, e para a CA de $3,83 \mathrm{~g}$ de concentrado $100 \mathrm{~g}$ de ganho de peso $^{-1}$, para cada dia de avanço no período de suplementação. Já para o GPMD, o comportamento foi quadrático, observando-se ponto de máximo ganho de peso aos 54,3 dias de suplementação.

SOUZA et al. (1998), avaliando o efeito da inclusão diária de 3,5g de levedura Saccharomyces cerevisia por animal, associado a dois níveis de volumoso na alimentação de cabras lactantes, observaram apenas aumento de $12 \%$ no teor de gordura no leite, sem alterações na produção de leite e no consumo diário de matéria seca.Os pesquisadores concluíram que a levedura é indicada como um estabilizante ruminal, por promover mudanças significativas na relação acetato: proprionato que influencia diretamente o teor de gordura e/ou que atua preventivamente sobre a ocorrência de disfunções ruminais. SANTOS et al. (2006) trabalharam com vacas em lactação que receberam dietas com $8 g$ de levedura Saccharomyces cerevisiae associados a dois teores de amido e verificaram aumento no teor de gordura do leite com o fornecimento de levedura, mantendo-se similar a produção de leite e aos demais parâmetros de composição do leite. Inferências de CHAUCHEYRESDURANT \& FONTY (2002) quanto ao uso de leveduras 
Tabela 3 - Pesos iniciais e finais das ovelhas e dos cordeiros e produção média de leite das ovelhas, de acordo com os diferentes níveis de suplementação com Saccharomyces cerevisiae.

\begin{tabular}{|c|c|c|c|c|c|c|}
\hline \multirow{2}{*}{$\begin{array}{l}\text { Níveis de } \\
\text { suplementação }\end{array}$} & \multicolumn{3}{|c|}{--------------------Ovelhas-------------------' } & \multicolumn{3}{|c|}{--------------------'Cordeiros-------------------- } \\
\hline & Peso inicial (kg) & $\begin{array}{l}\text { Produção leite } \\
\left.\text { (g dia }{ }^{1}\right)\end{array}$ & Peso final (kg) & Peso inicial (kg) & Peso final (kg) & Diferença (kg) \\
\hline $0 \mathrm{~g} \mathrm{dia}^{-1}$ & $99,2 \mathrm{~A}$ & $1367 \mathrm{~B}$ & 98,6 A & 19,9 A & $47,9 \mathrm{~A}$ & $28,0 \mathrm{~A}$ \\
\hline $0,4 \mathrm{~g} \mathrm{dia}^{-1}$ & 98,3 A & $1833 \mathrm{~A}$ & 95,4 B & $18,2 \mathrm{~A}$ & 43,6 B & $25,4 \mathrm{~B}$ \\
\hline 0,8 g dia $^{-1}$ & $100,3 \mathrm{~A}$ & 1263 B & 99,7 A & $20,4 \mathrm{~A}$ & $47,1 \mathrm{~A}$ & $26,7 \mathrm{AB}$ \\
\hline Média & 99,3 & 1488 & 97,9 & 19,5 & 46,1 & 26,7 \\
\hline
\end{tabular}

Médias seguidas de letras maiúsculas na coluna, para cada parâmetro, diferem pelo teste Tukey $(\mathrm{P}<0,05)$.

vivas na dieta de cordeiros recém-desmamados, na dose de $0,2 \mathrm{~g}$ animal ${ }^{-1} \mathrm{dia}^{-1}$, também mostraram melhorias no consumo de matéria seca e nos parâmetros relativos às características físico-químicas e de fermentação do rúmen, sugerindo que o probiótico acelerou a funcionalidade e a estabilidade microbiana ruminal frente à dieta controle.

Segundo PEREIRA et al. (2001), a atividade microbiana e suas funções no processo digestivo podem ocorrer sob pH ruminal abaixo de 5,5, condição muito freqüente por meio do uso excessivo de concentrado à dieta dos ovinos (acima de $2 \%$ do peso vivo), devido à rápida fermentação dos carboidratos não-estruturais e à intensa produção de ácidos graxos voláteis, o que, segundo VAN SOEST (1984), pode reduzir a digestão efetiva da fibra e diminuir o desempenho dos animais. O consumo diário de concentrado dos cordeiros, expresso em percentagem do peso vivo, obtido no presente estudo apresentou valor médio de $2,73 \%$ no terceiro período, sendo superior à média normal de utilização na produção ovina, o que resultou em redução de GPMD (491 contra $396 \mathrm{~g} \mathrm{dia}{ }^{1}$, respectivamente) do segundo para o terceiro período de avaliação, porém, de forma independente da inclusão de Saccharomyces cerevisiae à dieta alimentar dos cordeiros.

A inexpressão da atuação das leveduras vivas sobre os parâmetros relativos ao desempenho dos cordeiros, em creep-feeding, poderia ser reflexo da categoria animal utilizada, caracterizada como aquela dependente de uma fase de grandes transformações em termos de formato, funções e crescimento do aparelho gastrointestinal e adaptação aos alimentos sólidos e de altos teores de fibra (VAN SOEST, 1984). No entanto, tal afirmação não se confirma no presente trabalho, pois os animais, apesar de serem cordeiros lactentes, com idade superior a 40 dias e peso vivo superior a $19 \mathrm{~kg}$, mostraram altos consumos de alimentos, o que caracteriza que o aparelho gastro- intestinal funcionou à plenitude de suas funções biológicas. Outra explicação à ineficiência das leveduras sobre o desempenho dos cordeiros estaria nas características no uso de um concentrado com lenta degradação ruminal devido ao baixo grau de processamento do milho grão (moagem grosso) e da aveia branca (grãos inteiros machacados), em associoação com o fornecimento parcelado diariamente duas horas no período da manhã e duas horas no período da tarde, condição que impede a permanência de um ambiente ruminal com $\mathrm{pH}$ a valores inferiores de 5,5. ARCOS-GARCÍA et al. (2000), avaliando o efeito de duas cepas comerciais de leveduras vivas na dieta de cordeiros Suffolk com 30kg de peso vivo, na dose de $1 \mathrm{~g} \mathrm{dia}^{-1}$ de Saccharomyces cerevisiae, também não encontraram melhorias no desempenho animal, apesar de constatarem alterações benéficas no $\mathrm{pH}$ ruminal, visto que os parâmetros relativos à proporção molar dos ácidos graxos voláteis, à população de protozoários e à digestibilidade da matéria seca e da fibra em detergente neutro mantiveram-se similares tanto na comparação entre leveduras como na comparação com a dieta sem inclusão de leveduras vivas.

Evidenciou-se que cordeiros suplementados com 0,4g dia ${ }^{-1}$ de Saccharomyces cerevisiae tiveram menor desenvolvimento corporal $(43,6 \mathrm{~kg})$ e as ovelhas menor peso ao desmame $(95,4 \mathrm{~kg})$ frente aos demais tratamentos. Essa resposta se justifica possivelmente em função da produção de leite das ovelhas e não em função da ação dos cordeiros em relação ao consumo diário de concentrado e do ganho de peso diário (Tabela 3).

BERTIN et al. (2005) avaliaram o efeito da inclusão da levedura Saccharomyces cerevisiae sobre o desempenho de 236 bezerros holandeses no período de 21 a 200 dias de idade e verificaram que animais suplementados com levedura tiveram maior ingestão diária de matéria seca no período (521,3 contra 492,7kg), peso vivo final (227,8 contra $215,8 \mathrm{~kg})$ e ainda melhor conversão alimentar (2,97 contra 3,02) comparativamente 
à dieta controle. Já MIRANDA et al. (2001), verificaram um aumento de 4,2\% no consumo diário de ração (10,33 contra $10,09 \mathrm{~kg} \mathrm{dia}^{-1}$ de MS), o que resultou em um aumento de $6,2 \%$ no ganho de peso médio diário $(1,59$ contra $1,49 \mathrm{~kg} \mathrm{dia}^{-1}$ ) nos novilhos suplementados com a levedura Saccharomyces cerevisiae.

Os dados do presente trabalho mostraram inexpressão do nível de Saccharomyces cerevisiae sobre o desempenho dos cordeiros Ile de France, em condição do alto nível de consumo de concentrado praticado pelos mesmos no creep-feeding, em associação com a baixa participação de alimentos fibrosos na dieta alimentar e a alta produção leiteira das ovelhas. Esse resultado corrobora os dados obtidos por TRICARICO (2005), o que, no entanto, foi contraditório em relação à maioria dos trabalhos (MIRANDA et al., 2001; PEREIRA et al., 2001; BERTIN et al., 2005 e SANTOS et al., 2006), os quais mostraram resultados benéficos em condições de dietas de alta concentração de carboidratos solúveis.

\section{CONCLUSÕES}

O desempenho de cordeiros Ile de France, nascidos de parto simples, em sistema de creep-feeding, não foi alterado em função do nível de suplementação com leveduras vivas secas.

\section{REFERÊNCIAS}

AGRICULTURAL RESEARCH COUNCIL - ARC. The nutrients requirements of ruminants livestock. London: Technical review by on Agricultural Research Council working Party, 1980. 351p.

ANUALPEC - Anuário estatístico da produção animal. FNP. São Paulo: Camargo Soares, 2006. 362p.

ARCOS-GARCÍA, J.L. et al. Effect of two commercial yeast cultures with Saccharomyces cerevisiae on ruminal fermentation and digestion in sheep fed sugar cane tops. Production Science, Livestock, v.63, n.2, p.153-157, 2000.

ASSOCIATION OF OFFICIAL ANALYTICAL CHEMISTS A.O.A.C. Official methods of analysis. 16.ed. Washington, D.C.: AOAC, 1995. 2000p.

BERTIN, G. et al. Benefícios da suplementação de cultura de levedura (Yea-Sacc) no desempenho de bezerros. In: SIMPÓSIO BRASILEIRO DA INDÚSTRIA DE ALIMENTAÇÃO ANIMAL, 2.; CRIAR, INOVAR E ELEVAR BIOTECNOLOGIA NUTRICIONAL DA INDÚSTRIA DE ALIMENTAÇÃO ANIMAL, 2005, Curitiba. Anais... Curitiba: Alltech, 2005. p.66.

CALLAWAY, E.S.; MARTIN, S.A. Effects of a Saccharomyces cerevisiae culture on ruminal bacteria that utilize lactate and digest cellulose. Journal of Dairy Science, Chapaign, v.80, n.9, p.2035-2044, 1997.

CHAUCHEYRAS-DURANT, F. FONTY, G. Influence of a probiotic yeast (Saccharomyces cerevisiae CNCM I-1077) on microbial colonization and fermentations in the rumen of newborn lambs. Microbial Ecology in Health and Disease, Mississippi, v.11, n.1, p.30-36, 2002.

DAWSON, K.A.; HOPKINS, D.M. Differential effects of live yeast culture in animal production: A review of research over the last six years. Nicholasville: Alltech Technical Publications, 1992. 40p. (Supplement to the Proceedings of Alltech's 8th. Annual Symposium).

DAWSON, K.A. Some milestones in our understanding of yeast culture supplementation in ruminants and their implications in animal production systems. In: LYONS, T.P.; JACQUES, K.A. (Eds.). PROCEEDINGS OF ALLTECH'S ANNUAL SYMPOSIUM, 16, Nottingham, U.K. Proceedings... Nottingham, U.K.: Nottingham University, 2000. p.473-486.

DOREAU, M.; JOUANY, J.P. Effect of a Saccharomyces cerevisiae culture on nutrient digestion in lactating dairy cows, Journal Dairy Science, Savoy, v.81, n.12, p.3214-3221, 1998.

EZEQUIEL, J.M.B. et al. Balanço de nitrogênio e digestão total da proteína e energia de rações contendo farelo de algodão, levedura de cana-de-açúcar ou uréia, em ovinos. Revista Brasileira de Zootecnia, Viçosa, v.29, n.6, Supl.2, p.23322337, 2000

MIRANDA, L.F. et al. Desempenho e características da carcaça de novilhos Simental suplementados com probióticos. Scientia, Vila Velha, v.2, p.3-14, 2001.

MONTENEGRO, R.L.; SIQUEIRA, E.R. Velocidade de crescimento, características da carcaça, análise hormonal e morfológica do epitélio intestinal de cordeiros sob dois fotoperíodos. Ciência Rural, Santa Maria, v.32, n.6, p.10451050, 2002.

NEWBOLD, C.J. et al. Different strains of Saccharomyces cerevisiae differin their effects on ruminal bacterial numbers in vitro and in sheep. Journal of Animal Science, Champaigm, v.73, p.1811-1818, 1995.

NEWBOLD, C.J. et al. Mod of action of yeast Saccharomyces cerevisiae as a feed additive for ruminates. Bristish Journal of Nutrition, Cambridge, v.76, n.2, p.249-261, 1996.

PEREIRA, E.S. et al. Fontes nitrogenadas e uso de Saccharomyces cerevisiae em dietas à base de cana-de-açúcar para novilhos: parâmetros ruminais. In: REUNIÃO ANUAL DA SOCIEDADE BRASILEIRA DE ZOOTECNIA, 38., 2001, Piracicaba. Anais... Piracicaba: Sociedade Brasileira de Zootecnia: Gmosis, [2001]. p.908-909. CD-ROM.

PIRES, C.C. et al. Desempenho e características da carcaça de cordeiros de três grupos genéticos abatidos ao mesmo estágio de maturidade. Ciência Rural, Santa Maria, v.29, n.1, p.155158, 1999. 
RIBEIRO, E.L.A. et al. Ganho de peso e componentes do peso vivo em borregos Ile de France inteiros e castrados e Hampshire Down castrados abatidos aos doze meses de idade. Ciência Rural, Santa Maria, v.30, n.2, p.333-336, 2000.

ROSE, A.H. Yeast, a microorganism for all species: a theoretical look at its mod of action. In: LYONS, T.P. (Ed.). Biotechnology in the feed industry. Nicholasville: Alltech Technical, 1997. p.113-118.

SANTOS, F.A.P. et al. Desempenho de vacas em lactação recebendo dietas com diferentes teores de amido total, acrescidos ou não de leveduras (Saccharomyces cerevisiae). Revista Brasileira de Zootecnia, Viçosa, v.35, n.4, p.1568-1575, 2006.

SAS INSTITUTE. SAS/STAT user's guide: statistics, version 6. 4.ed. North Caroline, 1993. V.2, 943p.

SOUZA, C.A. et al. Efeito da levedura Saccharomyces cerevisiae e do nível de volumoso no desempenho produtivo de cabras lactantes. In: REUNIÃO ANUAL DA SOCIEDADE BRASILEIRA DE ZOOTECNIA, 35., 1998, Botucatu. Anais...
Botucatu: Sociedade Brasileira de Zootecnia, Gmosis, [1998]. p.239-241. CD-ROM.

TRICARICO, J.M. Otimizando a função ruminal: Benefícios de Beef-Sacc na produtividade animal. In: MALAGUIDO, A.; PRIETO, F. (Eds.). SIMPÓSIO BRASILEIRO DA INDÚSTRIA DE ALIMENTAÇÃO ANIMAL, 2.; CRIAR, INOVAR E ELEVAR - BIOTECNOLOGIA NUTRICIONAL DA INDÚSTRIA DE ALIMENTAÇÃO ANIMAL, 2005, Curitiba, PR. Anais... Curitiba: Simpósio Brasileiro Alltech, 2005. p.119-126.

TEDESCO, M.J. et al. Análise de solo, plantas e outros materiais. Porto Alegre: UFRGS - Departamento de Solos, 1985. 188p.

VAN SOEST, P.J. Nutritional ecology of the ruminant. 2.ed. Ithaca: Cornell University, 1984. 476p.

VAN SOEST, P.J. et al. Symposium: carbohydrate methodology, metabolism, and nutritional implications in dairy cattle. Methods for dietary fiber, neutral detergent fiber, and nonstarch polysaccharides in relation to animal nutrition. Journal of Dairy Science, Savoy, v.74, n.10, p.3583-3597, 1991. 